\title{
Telmisartan - an effective antihypertensive for 24-hour blood pressure control
}

\author{
Scott Chambers \\ CSF Medical Communications, Cheltenham, UK \\ Drugs in Context \\ DOI: http://dx.doi.org/10.7573/dic. 212220
}

Citation: Chambers, S. Telmisartan - an effective antihypertensive for 24-hour blood pressure control. Drugs in Context: e212220.

doi: $10.7573 /$ dic. 212220

Copyright: this is an open access article published under the terms of the Creative Commons License Deed (CG BY-NC-ND 3.0) which allows you to share, copy, distribute and transmit the work provided it is properly attributed. You may not use this work for commercial purposes. For further information on commercial use, contact publisher@justmedicalmedia.com or go to wrwre.drugsincontext.com/copyright.

Search criteria: English language articles were identified by searching the PubMed database using the search terms 'telmisartan' and 'hypertension'. Abstracts were evaluated and selected for further review according to our standard protocols. Bibliographies of individual articles were also assessed for additional articles of interest and the manufacturer of telmisartan was contacted and was invited to supply any additional data to that identified via the PubMed database.

Date of last literature search: 18 October 2007.

Conclusion: Telmisartan is a novel, highly selective AIIRA that provides effective blood pressure control over 24 hours and in particular reduces the morning surge in blood pressure, which is associated with adverse cardiovascular outcomes. Emerging evidence indicates that telmisartan also has renoprotective properties.

NB: This article was originally published by CSF Medical Communications Ltd (CSF) in Drugs in Context 2008;4(1):1-14. Drugs in Context and all CSF copyrights were acquired by Just Medical Media Ltd in 2009. 


\section{SUMMARY}

Hypertension can be managed effectively with a wide range of drugs from different classes. However, different combinations of these agents are frequently required for blood pressure to be sufficiently controlled for patients to reach guideline targets. Telmisartan, an angiotensin II receptor antagonist (AIIRA), is effective in controlling hypertension in a broad population of hypertensive patients, including the elderly and those with comorbid conditions (type 2 diabetes and renal impairment), when used as monotherapy or in combination with the thiazide diuretic, hydrochlorothiazide (HCTZ). Telmisartan, like other AIIRAs, blocks the effects of angiotensin II by competitively binding to angiotensin II type 1 (AT1) receptors. It has a longer plasma halflife than all of the other AIIRAs currently available, which accounts for its extended control of blood pressure over a 24-hour period. This has implications for the control of the early morning surge in blood pressure and thus may help to prevent excess cardiovascular mortality and morbidity (e.g. myocardial infarction [M] or strokes) which occur at a greater frequency between 6 am and noon. Evidence from clinical trials has shown that telmisartan, with or without HCTZ, has a good tolerability and safety profile, and is better tolerated than angiotensin-converting enzyme (ACE) inhibitors. Taken together, these observations indicate that telmisartan represents a valuable first-line treatment option for the management of hypertension.

Key words: hypertension; cardiovascular disease; renovascular disease; angiotensin receptor antagonist; telmisartan; Micardis.

\section{HYPERTENSION: A PERSPECTIVE}

Hypertension is a major public health problem and is a leading cause of death and disability across the world. Currently, about 1 billion people are living with hypertension globally. Despite a wealth of research, the pathophysiology of essential hypertension is not fully understood. However, a broad range of interventions are now available and treatment algorithms for the management of hypertension continue to evolve as data accumulates from large, multinational clinical trials. Despite the availability of these different interventions, improving the management of hypertension in practice continues to be a major challenge to the healthcare profession.

Angiotensin II, a potent vasoconstrictor, is a major determinant of blood pressure and is implicated in the pathogenesis of hypertension. Drugs that modify the renin-angiotensinaldosterone system (RAAS), such as the ACE inhibitors and AIIRAs, are widely accepted agents for the management of hypertension. As AIIRAs block the effects of angiotensin II generated by pathways other than through the RAAS (e.g. most notably by the enzyme chymase) by selective binding to the AT1 receptor, AIIRAs are considered to be more specific than ACE inhibitors. Furthermore, ACE inhibitor treatment can lead to an accumulation of bradykinin - a vasodilator but also an inflammatory mediator - which can result in side-effects such as cough. Angiotensin II also mediates vascular hypertrophy and the development of atherosclerosis by stimulating the growth of vascular smooth muscle cells. It is also involved in the development of left ventricular hypertrophy $(\mathrm{LVH})$ and also plays a role in the progression of renal disease. Consequently, antihypertensive therapies that block the effects of angiotensin II have been shown to induce regression of LVH and improve renal haemodynamics in patients with renal disease. $^{1,2}$

Telmisartan is a non-peptide AIIRA that binds selectively to AT1 receptors, thereby blocking the physiological actions of angiotensin II. It has a number of pharmacological properties that translate into an extended duration of 
antihypertensive efficacy over the entire 24-hour dosing period and particularly during the final 6 hours of dosing. This property has the potential to reduce the increased incidence of adverse cardiovascular outcomes that coincide with the morning surge in blood pressure.

\section{PHARMACOLOGY}

The AIIRAs exhibit considerable heterogeneity in chemical structure, which influences their respective pharmacological properties. Telmisartan is more lipophilic than losartan, candesartan, irbesartan and valsartan, ${ }^{3,4}$ which permits good tissue penetration. There are also differences in terms of affinity for the AT1 receptor, which translate into differences in antihypertensive potency. ${ }^{5}$ Telmisartan is a highly selective, 'insurmountable' AT1 receptor antagonist, which dissociates slowly once bound to the AT1 receptor (Table 1), thereby contributing to its long duration of action. ${ }^{6}$

\section{Pharmacokinetics}

Telmisartan is rapidly absorbed from the gastrointestinal tract. ${ }^{7,8}$ The absolute bioavailability of telmisartan is approximately $43 \% .^{8}$ The volume of distribution of approximately 500
$\mathrm{L}$ is the highest of all the AIIRAs whilst its elimination half-life ( $\sim 24$ hours) is the longest (Table 1).,47,8 These properties ensure sustained antihypertensive activity at the end of the dosing interval, a time which corresponds to the highest surge in blood pressure and the greatest incidence of cardiovascular complications. ${ }^{3}$

\section{Effects on PPAR- $\gamma$}

Peroxisome proliferator-activated receptor $\gamma($ PPAR $-\gamma)$ is a nuclear transcription factor involved in carbohydrate and lipid metabolism. ${ }^{9,10}$ Telmisartan acts as a partial agonist of PPAR- $\gamma$ at therapeutic doses in contrast to other AIIRAs. ${ }^{9,11}$ Telmisartan also reduces glucose and triglyceride levels and increases glucose uptake and GLUT4 expression, factors that may translate into a favourable metabolic profile and a potential insulin-sensitising activity of the drug. ${ }^{9,11}$

\section{CLINICAL EFFICACY}

\section{The importance of 24-hour blood pressure control}

Ideal attributes for an antihypertensive include provision of 24-hour blood pressure control and attenuation of the early morning surge in

Table 1. Comparative pharmacology of the AIIRAs.

\begin{tabular}{|c|c|c|c|c|c|c|c|c|c|c|}
\hline Drug & $\begin{array}{l}\text { Active } \\
\text { metabolite }\end{array}$ & $\begin{array}{l}t_{\max } \\
\text { (hours) }\end{array}$ & $\begin{array}{l}\text { Bioavailability } \\
(\%)\end{array}$ & $\begin{array}{l}\text { Volume of } \\
\text { distribution } \\
\text { (L) }\end{array}$ & $\begin{array}{l}\text { Elimination } \\
\text { half-life } \\
\text { (hours) }\end{array}$ & Metabolism & $\begin{array}{l}\text { Excreted } \\
\text { renally } \\
(\%)\end{array}$ & $\begin{array}{l}\mathrm{AT}_{1} \\
\text { receptor } \\
\text { binding }\end{array}$ & $\begin{array}{l}\text { PPAR- } \gamma \\
\text { agonist } \\
\text { activity }\end{array}$ & $\begin{array}{l}\text { Lipophilicity } \\
\left(\log P^{\mathrm{b}}\right)\end{array}$ \\
\hline Candesartan & Yes & $3-4$ & 42 & 9 & $3.5-4.0$ & CYP 2C9 & 33 & 133 & None & -0.96 \\
\hline Eprosartan & No & $1-2$ & 15 & 13 & $5-7$ & Not CYP & 7 & $\mathrm{~N} / \mathrm{A}$ & None & $\mathrm{N} / \mathrm{A}$ \\
\hline Irbesartan & No & $1.5-2$ & $60-80$ & 53-93 & $11-15$ & CYP 2 C9 & 20 & $\mathrm{~N} / \mathrm{A}$ & None & +1.48 \\
\hline $\begin{array}{l}\text { Losartan } \\
\text { (Active } \\
\text { metabolite) }\end{array}$ & Yes & $\begin{array}{l}1 \\
(3-4)\end{array}$ & 33 & 34 & $\begin{array}{l}2 \\
(6-9)\end{array}$ & CYP 2C9/3A4 & 35 & $\begin{array}{l}67 \\
(81)\end{array}$ & None & $\begin{array}{l}\mathrm{N} / \mathrm{A} \\
(-2.45)\end{array}$ \\
\hline Olmesartan & Yes & 2 & 26 & $16-29$ & $\sim 13$ & Not CYP & $35-50$ & 166 & None & $\mathrm{N} / \mathrm{A}$ \\
\hline Telmisartan & No & $0.5-1$ & 43 & 500 & 24 & Not CYP & 0.5 & 213 & Partial & +3.20 \\
\hline Valsartan & No & 2 & 25 & 17 & 9 & Not CYP & 13 & 70 & None & -0.95 \\
\hline
\end{tabular}

aDissociation half-life from the $\mathrm{AT}_{1}$ receptor $\mathrm{min}^{-1}$.

${ }^{\mathrm{b}} \log P$ describes the partition coefficient (n-octanol/buffer at $\mathrm{pH} 7.4$ ).

$\mathrm{AT}_{1}$, angiotensin type-1 receptor; CYP, cytochrome P450; N/A, not available; $t_{\max }$ (hours), time to reach peak plasma concentration; PPAR, peroxisome proliferator-activated receptor. 
blood pressure. ${ }^{12}$ Cerebral haemorrhage and MI are precipitated by rapid increases in blood pressure, such as those that occur in the morning in both normotensive and hypertensive patients. Significantly, most strokes occur between 8 am and noon and most MIs occur between 6 am and noon. ${ }^{13,14}$ Consequently, antihypertensive drugs should provide 24-hour efficacy with a oncedaily dose, with at least $50 \%$ of the peak effect remaining at the end of 24 hours. ${ }^{15}$

\section{Meta-analyses}

A meta-analysis evaluated ambulatory blood pressure monitoring (ABPM) data from five clinical trials. ${ }^{16}$ Patients $(n=1,566)$ were treated with once-daily placebo, telmisartan, $40 \mathrm{mg}$ or $80 \mathrm{mg}$, losartan, $50 \mathrm{mg}$, valsartan, $80 \mathrm{mg}$, and amlodipine, $5 \mathrm{mg}$. Both telmisartan doses provided effective blood pressure control during the morning period (i.e. 6.00-11.59 am [Figure 1]). Furthermore, telmisartan, $80 \mathrm{mg}$, provided superior reductions in diastolic blood pressure (DBP) and systolic blood pressure (SBP) compared with losartan, $50 \mathrm{mg}$, or valsartan, $80 \mathrm{mg}$ (all comparisons $p<0.0125)$. An additional metaanalysis compared the efficacy of telmisartan and losartan at reducing mean DBP during the last 6 hours of the dosing interval. ${ }^{17}$ Data were extracted from two randomised, double-blind, doubledummy, titration-to-response studies in patients with mild-to-moderate hypertension $(n=720)$. All patients received telmisartan, $40 \mathrm{mg} /$ day, or losartan, $50 \mathrm{mg} /$ day, with dose titration after 4 weeks to telmisartan, $80 \mathrm{mg} /$ day, or losartan, 100 $\mathrm{mg}$ /day, respectively, if DBP was $90 \mathrm{mmHg}$ or higher. Telmisartan elicited greater reductions in DBP and SBP than losartan during the last 6 hours of the 24-hour dosing interval (6.6 vs 5.1 and 9.9 vs $7.8 \mathrm{mmHg}$, respectively; $p<0.01$ and $p=0.01$, respectively).

\section{Telmisartan vs other AIIRAs}

\section{Telmisartan vs losartan}

Superior and longer lasting control of blood pressure has been demonstrated for telmisartan (40 or $80 \mathrm{mg} /$ day) over losartan (50 mg/day) in a randomised, placebo-controlled, doubleblind trial in 223 patients with mild-to-moderate

Figure 1. Mean reduction in SBP and DBP during the morning with various antihypertensives. ${ }^{16}$
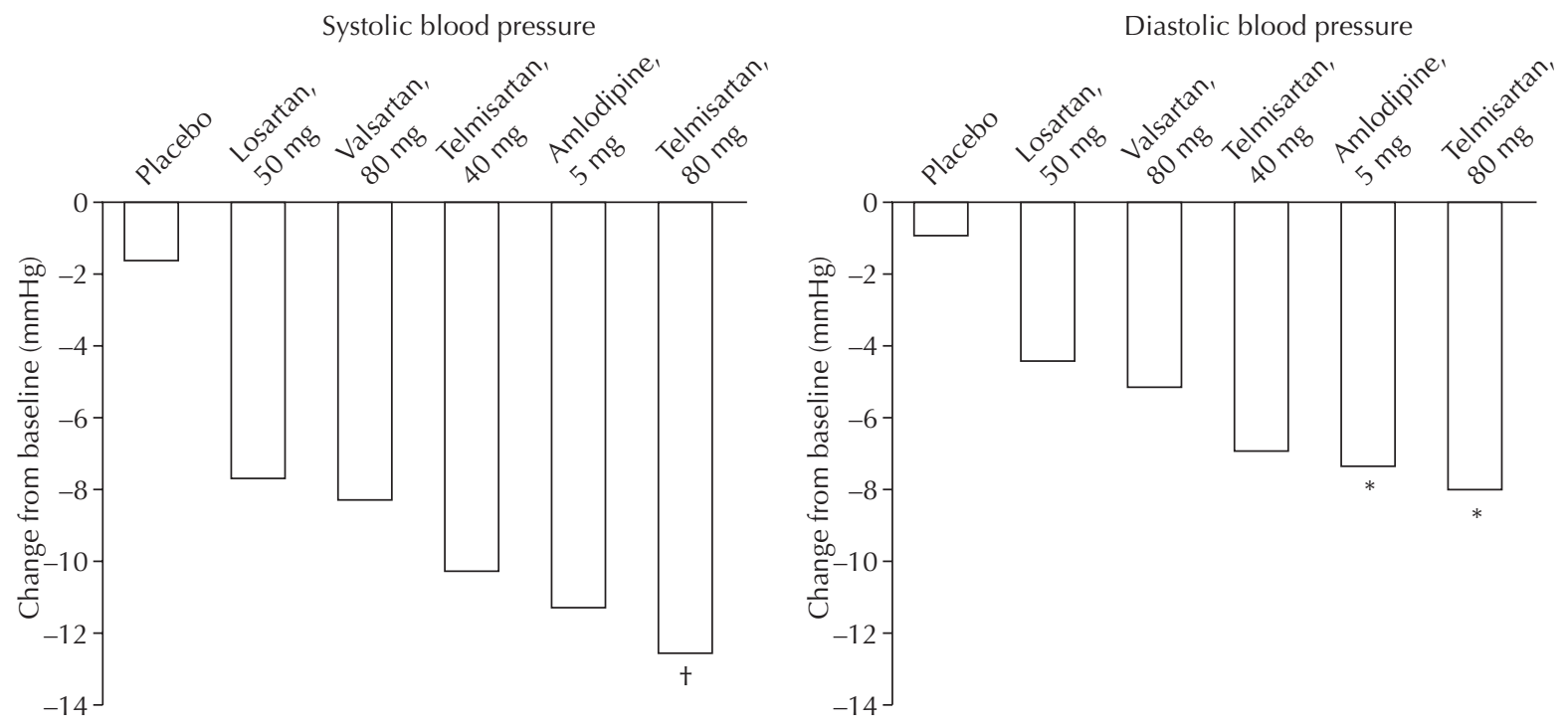

${ }^{*} p<0.0125$, telmisartan, $80 \mathrm{mg}$, or amlodipine, $5 \mathrm{mg}$, vs losartan, $50 \mathrm{mg}$, or valsartan, $80 \mathrm{mg}$.

${ }^{+} p<0.0125$, telmisartan, $80 \mathrm{mg}$, vs losartan, $50 \mathrm{mg}$, or valsartan, $80 \mathrm{mg} ; p<0.05 \mathrm{vs}$ telmisartan, $40 \mathrm{mg}$. 
hypertension. ${ }^{18}$ All active treatments provided significant reductions in patients' mean 24-hour SBP or DBP $(p<0.05)$. During the period 18-24hours after dosing, the reductions in SBP and DBP with telmisartan, $40 \mathrm{mg}$ (10.7 and 6.8 $\mathrm{mmHg}$, respectively), and telmisartan, $80 \mathrm{mg}$ (12.2 and $7.1 \mathrm{mmHg}$, respectively), were significantly greater than those achieved with losartan $(6.0$ and $3.7 \mathrm{mmHg}$, respectively; $p<0.05)$. In addition, telmisartan, $80 \mathrm{mg}$, provided greater reductions in SBP and DBP than losartan throughout the 24-hour period $(p<0.05)$, whilst telmisartan, 40 $\mathrm{mg}$, produced greater reductions in blood pressure during the night time (i.e. $10.01 \mathrm{pm}-5.59 \mathrm{am}$ ) and the morning (i.e. 6.00-11.59 am) than did losartan (all comparisons $p<0.05$ ). Furthermore, the reductions in $\mathrm{SBP}(3.7 \mathrm{mmHg})$ and $\mathrm{DBP}(2.2$ $\mathrm{mmHg}$ ) observed during the period 18-24-hours post-dosing with losartan were not significantly different from the reductions observed with placebo indicating loss of antihypertensive efficacy.

\section{Telmisartan vs valsartan}

A number of trials have compared the relative antihypertensive efficacy of telmisartan and valsartan. ${ }^{19,20}$ A randomised, double-blind, parallel-group, forced-titration study evaluated the antihypertensive effects of telmisartan (40 $\mathrm{mg} /$ day for 2 weeks, titrated to $80 \mathrm{mg} /$ day for 4-6 weeks) and valsartan (80 mg/day for 2 weeks, titrated to $160 \mathrm{mg} /$ day for 4-6 weeks) in controlling early morning blood pressure in patients with mild-to-moderate hypertension $(\mathrm{n}=490) .{ }^{19}$ Telmisartan reduced SBP and DBP, as determined by ABPM, over the final 6 hours of the dosing interval by a greater extent than valsartan $(-11.0 /-7.6 \mathrm{mmHg}$ vs $-8.7 /-$ $5.8 \mathrm{mmHg} ; p=0.02$ and $p=0.01$, respectively). Reductions in mean 24-hour blood pressure were also greater with telmisartan than with valsartan, though this difference did not reach statistical significance $(-10.3 /-6.9 \mathrm{mmHg}$ vs $-8.7 /-5.9 \mathrm{mmHg} ; p=0.06$ in both cases). Both agents were well tolerated in this study, with a similar incidence of adverse events in both treatment groups. In contrast, a smaller randomised, open-label, parallel-group study $(\mathrm{n}=70)$, which compared telmisartan and valsartan administered at their maximum recommended daily doses (telmisartan, $80 \mathrm{mg}$ / day, and valsartan, $160 \mathrm{mg} /$ day) for 3 months, reported that valsartan was more effective in lowering blood pressure over 24 hours, despite its shorter elimination half-life. ${ }^{20}$ Thus, whilst both drugs significantly reduced the 24-hour mean blood pressure as determined by ABPM, valsartan reduced SBP and DBP by a greater extent than telmisartan $(-18.6 /-12.1 \mathrm{mmHg}$ vs -10.8/-8.4 mmHg; $p<0.001)$. Twenty-four-hour pulse pressure was also significantly reduced with valsartan, but not telmisartan. However, the trough/peak ratio and smoothness index (measures of the duration and the homogeneity of the antihypertensive effect, respectively) for SBP was higher for telmisartan than for valsartan.

\section{Telmisartan vs ACE inhibitors}

\section{Telmisartan vs enalapril}

ABPM has been used to compare relative blood pressure control afforded by telmisartan and enalapril in a 12-week, prospective, randomised, open-label, blinded-endpoint trial. ${ }^{21}$ Patients $(\mathrm{n}=522)$ with mild-to-moderate hypertension received telmisartan, $40 \mathrm{mg}$, or enalapril, $10 \mathrm{mg}$, both given once daily, with titration to 80 and $20 \mathrm{mg}$ once daily, respectively, in order to control DBP to below $90 \mathrm{mmHg}$. Telmisartan and enalapril produced similar reductions in SBP and DBP over all ABPM periods evaluated (last 6 hours, 24 hours, daytime and night time). Nevertheless, a greater reduction in seated trough DBP was observed in patients treated with telmisartan than with enalapril (-9.69 vs -7.67 $\mathrm{mmHg}$, respectively; $p<0.01$ ), whilst more patients 
receiving telmisartan than enalapril achieved a seated DBP response (59 vs 50\%, respectively; $p<0.05)$. Compared with telmisartan, enalapril was associated with a higher incidence of cough and hypotension (8.9 vs $0.8 \%$ and 3.9 vs $1.1 \%$, respectively; no $p$-values reported).

\section{Telmisartan vs lisinopril}

Telmisartan was compared with lisinopril as monotherapy and in combination with hydrochlorothiazide (HCTZ) in a 1-year, randomised, double-blind, double-dummy, parallel-group, dose-titration study in 578 patients with mild-to-moderate hypertension. ${ }^{22}$ Patients were randomised to telmisartan, $40 \mathrm{mg}$ / day, or lisinopril, $10 \mathrm{mg} /$ day, with dose titration to $80 \mathrm{mg} /$ day and then $160 \mathrm{mg} /$ day in the case of telmisartan or $20 \mathrm{mg} /$ day and then $40 \mathrm{mg}$ / day for lisinopril in order to control DBP to below 90 mmHg. HCTZ, 12.5-25 mg/day, was added to maintain DBP control. Similar proportions of patients had their blood pressure controlled with telmisartan and lisinopril monotherapy (67 and 63\%, respectively). By the end of the study, supine DBP was controlled in 83 and $87 \%$ of patients receiving telmisartan and lisinopril, respectively. Fewer treatment-related side-effects occurred in patients given telmisartan than lisinopril (28 vs 40\%, respectively; $p=0.001$ ), with a lower incidence of treatment-related cough (3 vs $7 \%$, respectively; $p=0.018$ ) and discontinuation due to cough (0.3 vs $3.1 \%$, respectively; $p=0.007)$ with telmisartan.

\section{Telmisartan vs perindopril}

The antihypertensive efficacy of telmisartan and perindopril has been compared in a prospective, randomised, open-label, parallel-group study in patients with mild-to-moderate hypertension $(\mathrm{n}=441) .{ }^{23}$ Patients received telmisartan, $40 \mathrm{mg}$, or perindopril, $4 \mathrm{mg}$, for 6 weeks, and those whose clinic DBP was not controlled (i.e. $\geq 90 \mathrm{mmHg}$ ) had their dose of telmisartan or perindopril doubled for the final 6 weeks of the study. A greater reduction in trough DBP occurred in patients receiving telmisartan compared with those given perindopril (6.6 vs $5.1 \mathrm{mmHg}$, respectively; $p=0.018$ ). A smaller proportion of patients required dose titration in the telmisartan group than in the perindopril group (41 vs 55\%, respectively; $p=0.005$ ). The overall incidence of adverse events was comparable (34 vs $32 \%$, respectively; no $p$-value reported), and most were mild-to-moderate in intensity and transient in nature. However, the incidence of cough was less frequent in patients receiving telmisartan than those given perindopril ( $<1$ vs $5 \%$, respectively; $p=0.007)$.

\section{Telmisartan vs ramipril}

Two identical 14-week studies (PRISMA I and II) investigated the relative effects of telmisartan (40-80 $\mathrm{mg} /$ day) and ramipril (5-10 mg/day) upon blood pressure lowering in the final 6 hours of the dosing interval. ${ }^{24,25}$ The similarity in the design of both studies allowed for the pooling of data sets in a prespecified analysis. ${ }^{26}$ Each study recruited approximately 800 patients with mild-to-moderate hypertension and employed a prospective, randomised, open-label, blindedendpoint (PROBE) design. In both the European (PRISMA I) and North American studies (PRISMA II), telmisartan elicited superior blood pressure-lowering efficacy in the final 6 hours of the dosing interval compared with ramipril. Thus, after 14 weeks of treatment, mean blood pressure reductions in the early morning hours over ramipril were $3.7 / 2.7 \mathrm{mmHg}$ in PRISMA I $(p<0.0001)$ and $4.7 / 3.5 \mathrm{mmHg}$ in PRISMA II $(p<0.0001)$ (Figure 2). Telmisartan was also superior to ramipril on a range of secondary endpoints, including over the entire 24-hour dosing interval and during the day and night time (all comparisons $p<0.001$ ). A greater proportion of patients in both studies also achieved DBP control (<80 mmHg) with telmisartan (36 vs $28 \%$ in PRISMA I and 44 vs 22\% in PRISMA II). Patients in the ramipril group experienced a significantly higher incidence of cough compared 
Figure 2. Mean changes in DBP across the dosing interval with telmisartan and ramipril. Data from PRISMA I (left) and PRISMA II (right).
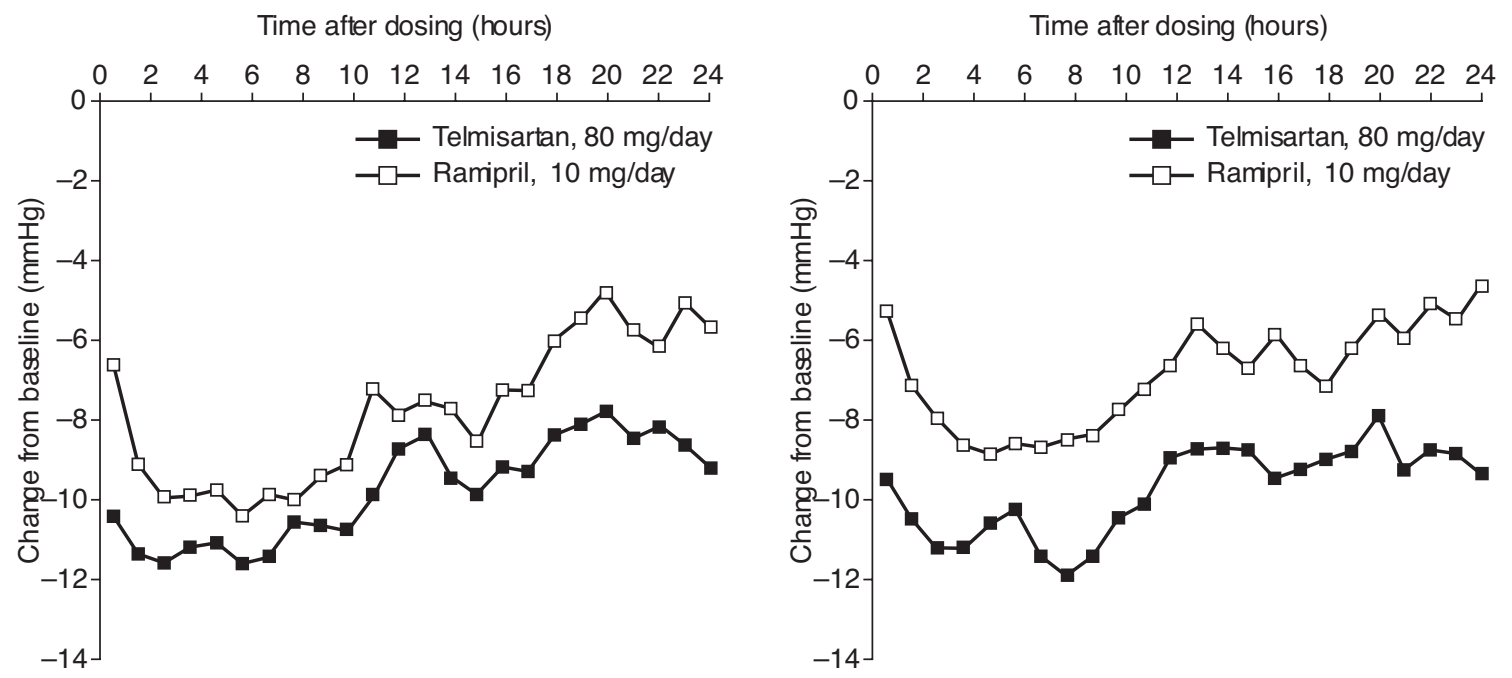

$\mathrm{p}<0.001$ for telmisartan, $80 \mathrm{mg}$, vs ramipril, $10 \mathrm{mg}$, in 24-hour mean blood pressure.

with the telmisartan group $(5.7$ os $0.5 \%$ in PRISMA I and 10.1 and $1.5 \%$ in PRISMA II). The pooled data analysis grouped patients into quartiles according to the magnitude of their early morning surge in blood pressure at baseline. ${ }^{26}$ In patients in the highest quartile who experienced a surge of $37 \mathrm{mmHg}$ or higher, telmisartan reduced the magnitude of the early morning systolic blood pressure surge by a significantly greater degree than did ramipril $(-12.7$ vs -7.8 $\mathrm{mmHg} ; p=0.0004)$.

\section{Telmisartan vs $\beta$-blockers}

Telmisartan is at least as effective as atenolol for the treatment of hypertension as demonstrated by one study in 533 patients with mild-to-moderate hypertension. ${ }^{27}$ This 26 -week trial reported a full morning mean supine DBP response in similar proportions of telmisartan- and atenolol-treated patients (84 and 78\%, respectively). However, an SBP response was achieved in more patients receiving telmisartan than atenolol (80 vs 68\%, respectively; $p=0.003)$. Both treatments were well tolerated, with most adverse events being of mild or moderate severity.

\section{Telmisartan vs calcium-channel blockers}

A 12-week trial has compared telmisartan with the calcium-channel blocker, amlodipine, and placebo. ${ }^{28}$ Patients with mild-to-moderate hypertension $(n=232)$ were given placebo or telmisartan, $40 \mathrm{mg} /$ day, or amlodipine, $5 \mathrm{mg}$ / day, with doses of telmisartan and amlodipine increased to up to $120 \mathrm{mg}$ and $10 \mathrm{mg} /$ day, respectively, in order to control DBP below 90 $\mathrm{mmHg}$. No difference was apparent between the telmisartan and amlodipine groups, with both agents reducing supine blood pressure by a similar extent (both $p<0.001$ vs placebo). In addition, telmisartan and amlodipine reduced 24-hour systolic and diastolic ABPM (both $p<0.001$ vs placebo). However, when individual intervals were investigated using ABPM, telmisartan reduced DBP by a greater extent than amlodipine during the night time (10 pm-6 am) and over the final 4 hours of the dosing interval $(p<0.05)$. Heart rates were also lower in patients treated with telmisartan during the final 4 hours $(-4.0$ vs +0.5 beats/minute, respectively; $p=0.003)$. Although telmisartan and amlodipine were generally well tolerated, drug- 
related oedema occurred more frequently in the amlodipine group compared with telmisartan $(p=0.001)$ or placebo $(p=0.03)$.

\section{Telmisartan in combination with other antihypertensives}

Several trials have investigated various combinations of telmisartan with other antihypertensive agents, principally HCTZ. In general, these studies have shown that the antihypertensive potency of telmisartan/ HCTZ combinations is superior to that achieved with telmisartan monotherapy. ${ }^{29-31}$ Furthermore, telmisartan/HCTZ combination is also generally well tolerated. ${ }^{32}$ Telmisartan (40 or $80 \mathrm{mg} /$ day) in combination with HCTZ, $12.5 \mathrm{mg} /$ day was compared with losartan, 50 $\mathrm{mg} /$ day. plus HCTZ, $12.5 \mathrm{mg} /$ day, in patients with mild-to-moderate hypertension $(\mathrm{n}=597) .{ }^{33}$ Telmisartan/HCTZ, 80/12.5 mg/day, reduced 24-hour DBP by $2.3 \mathrm{mmHg}$ more than losartan/HCTZ $(p<0.001)$. Moreover, both doses of telmisartan reduced blood pressure by 1.8 and $2.5 \mathrm{mmHg}$ more than those receiving the losartan/HCTZ combination during the final 6 hours of the dosing interval $(p<0.05$ and $p<0.001$, respectively). Similar observations were reported for $\mathrm{SBP}(p<0.05$ in favour of both telmisartan/HCTZ combinations). A large study with a PROBE design $(n=805)$ evaluated whether two telmisartan/HCTZ combinations (40/12.5 mg/day and 80/12.5 mg/day) were superior to losartan/HCTZ (50/12.5 mg/day) in reducing mean DBP during the last 6 hours of the dosing interval. ${ }^{34}$ Compared with the losartan-based regimen, reductions in mean DBP in the final 6 hours were significantly greater in both telmisartan groups (mean difference: 2.0 $\mathrm{mmHg}[p=0.0031]$ and $2.8 \mathrm{mmHg}[p=0.0003]$, respectively). Telmisartan/HCTZ (80/25 mg/ day) was also compared with valsartan/HCTZ (160/25 mg/day) in a large, placebo-controlled trial of 1,066 hypertensive patients. ${ }^{19}$ The telmisartan-based regimen elicited significantly greater reductions in blood pressure compared with valsartan/HCTZ (-24.0/-17.6 $\mathrm{mmHg}$ vs $-21.2 /-16.1 \mathrm{mmHg}$; $p=0.004$ for SBP and $p=0.019$ for DBP).

\section{Naturalistic studies}

Although community-based studies are subject to observer bias, they provide useful additional information regarding the management of chronic conditions in a more naturalistic setting. A large-scale $(n=1,619)$ practice-based trial (MICCAT 2 ${ }^{35}$ ) evaluated the effects of telmisartan monotherapy and telmisartan in combination with HCTZ on 24-hour blood pressure profiles. ${ }^{36}$ Enrolled patients were either untreated or already receiving antihypertensive treatment at baseline and were then started or switched to telmisartan, $40 \mathrm{mg} /$ day, at the start of the trial. After 2 weeks, telmisartan was titrated to $80 \mathrm{mg} /$ day and HCTZ, 12.5 $\mathrm{mg} /$ day, was added after a further 4 weeks if blood pressure persisted above 140/85 mmHg. The average blood pressure reduction in the early morning was $-11.5 /-7.0 \mathrm{mmHg}$, with similar reductions observed in the monotherapy $(-15.0 /-9.0 \mathrm{mmHg})$ and combination therapy groups $(-19.0 /-12.0 \mathrm{mmHg})$. Early morning blood pressure readings fell by a greater extent in patients with the largest morning surges in blood pressure at baseline $(-17.2 /-$ $10.1 \mathrm{mmHg}$ ). Reductions in blood pressure, determined either by office measurements or ABPM, were also observed in the subgroup of patients who were previously treated with alternative antihypertensives, with the decreases remaining significant for comparisons with each of the drug classes used previously. ${ }^{37}$

\section{Special patient populations}

\section{Elderly patients}

Isolated systolic hypertension (ISH) is common in the elderly and is often difficult to manage, 
with patients frequently requiring combination therapy to achieve SBP control. A recent 14-week, open-label, blinded-endpoint trial has compared the effects of telmisartan (40-80 mg/day) and amlodipine (5-10 mg/ day), both given in combination with HCTZ (12.5 mg/day), in an elderly population (aged $\geq 60$ years; $n=1,000$ ) with predominantly systolic hypertension. ${ }^{38}$ Telmisartan/HCTZ and amlodipine/HCTZ reduced SBP over the final 6 hours of the dosing interval by a similar magnitude $(-18.3$ and $-17.4 \mathrm{mmHg}$, respectively; $p=0.2520$ ) as determined by ABPM. However, over the entire 24-hour dosing period, telmisartan/HCTZ was superior to amlodipine/ HCTZ ( -19.3 and $-17.2 \mathrm{mmHg}$, respectively; $p=0.001)$ and yielded higher SBP control rates (65.9 and 58.3\%, respectively; $p=0.0175$ ). A benign safety and tolerability profile is important when treating elderly patients. The frequency of treatment-related adverse events (8.0 and $33.4 \% ; p<0.0001)$ and discontinuations from treatment (5.0 and $11.3 \%$, respectively) were lower with telmisartan than with amlodipine, with a substantially higher incidence of peripheral oedema reported in the amlodipine group (1.2 and $24.3 \%$, respectively). A further study reported that 24 weeks' treatment with telmisartan/HCTZ (80/12.5 mg/day) reduced 24-hour, day and night time ABPM values by a greater extent than lisinopril/HCTZ (20/12.5 $\mathrm{mg} /$ day) in a population of elderly hypertensives $(\mathrm{n}=160) .{ }^{39}$ As high blood pressure is related to cognitive impairment in later life, it is interesting to note that some components of cognitive function were improved with telmisartan but not with lisinopril.

\section{Patients with type 2 diabetes and the metabolic syndrome}

Patients with type 2 diabetes and the metabolic syndrome are at a substantially increased risk of adverse cardiovascular and renal outcomes and require stringent blood pressure control. A double-blind, placebo-controlled study of 119 patients with type 2 diabetes and mild hypertension evaluated the relative antihypertensive efficacy of 12 months' treatment with telmisartan (40 $\mathrm{mg} /$ day) and eprosartan (600 mg/day). ${ }^{40}$ Both telmisartan and eprosartan reduced seated trough SBP compared with baseline (mean reductions: -8 and $-7 \mathrm{mmHg}$, respectively; $p<0.01$ vs baseline). Although both drugs reduced seated trough DBP, the DBP-lowering effect of telmisartan was more profound than eprosartan $(-8$ and $-4 \mathrm{mmHg}$, respectively; $p<0.05)$. Interestingly, the plasma lipid profile was also significantly improved with telmisartan, but not with eprosartan; telmisartan reduced total cholesterol $(p<0.01)$, low density lipoprotein cholesterol $(p<0.01)$ and triglyceride levels $(p<0.05)$. Telmisartan treatment was also associated with significant reductions in total cholesterol $(-9 \%)$ and low density lipoprotein cholesterol $(-11.5 \%)$ in a comparative study with the calcium-channel blocker, nifedipine $(-2$ and $-1.5 \%$, respectively; both comparisons $\mathrm{p}<0.01$ in favour of telmisartan). ${ }^{40}$ Telmisartan and nifedipine reduced blood pressure by a similar extent. A further study evaluated the blood pressure-lowering effects of telmisartan and valsartan, given in combination with HCTZ, in a population of overweight or obese patients with type 2 diabetes and mild-to-moderate hypertension $(\mathrm{n}=840) .{ }^{41}$ Patients were randomised to telmisartan, $80 \mathrm{mg} /$ day, or valsartan, 160 $\mathrm{mg} /$ day, for 4 weeks followed by the addition of HCTZ, $12.5 \mathrm{mg} /$ day, for 6 weeks. Patients in the telmisartan/HCTZ group had significantly greater reductions in SBP and DBP compared with the valsartan/HCTZ group (between group difference: -3.9 and $-2.0 \mathrm{mmHg}$ for SBP and DBP; $p<0.0001$ and $p=0.0007$, respectively).

\section{Patients with diabetic nephropathy}

The landmark DETAIL study compared the relative renoprotective effects of telmisartan and enalapril in patients with mild-tomoderate hypertension and early type 2 
diabetic nephropathy. ${ }^{42}$ Two hundred and fifty patients were randomised to telmisartan (40-80 mg/day) or enalapril (10-20 mg/day). Telmisartan conferred similar renoprotective effects as enalapril. Thus, after 5 years, the difference between telmisartan and enalapril in the decline in glomerular filtration rate (GFR) was $-3.1 \mathrm{~mL} /$ minute per $1.73 \mathrm{~m}^{2}(95 \%$ CI: -7.6 to 1.6$)$, satisfying the predefined criterion for non-inferiority. Both telmisartan and enalapril were also associated with similar and low rates of all-cause mortality (about 5\% in both groups). ${ }^{42,43}$ The results from DETAIL have been complemented by data from a study which examined endothelial function in the renal vasculature of 96 type 2 diabetics with hypertension and normo-/microalbuminuria. Renal endothelial function was significantly improved with both telmisartan (40-80 mg/ day) and ramipril (5-10 mg/day) ( $p<0.001$ and $p<0.05$ for telmisartan and ramipril vs baseline, respectively). However, telmisartan significantly improved renal plasma flow (by $27.3 \mathrm{~mL} /$ minute; $p<0.05$ vs baseline) and decreased vascular resistance (by $\sim 7 \% ; p<0.05$ ) at rest (i.e. in the absence of NG-monomethyl-L-arginine (L-NMMA) infusion), whereas ramipril had no effect. Despite low levels of albuminuria at baseline, telmisartan also elicited a significant reduction in albuminuria (reduced from 9 to $7.2 \mathrm{mg} / 24$ hours; $p=0.022$ ), whereas ramipril had no effect.

The INNOVATION study reported that telmisartan delayed the onset of overt nephropathy in a population of 527 normo- and hypertensive patients with type 2 diabetes and incipient microalbuminuria. ${ }^{44}$ Transition rates to overt nephropathy at 1 year were 16.7, 22.6 and 49.9\% with telmisartan, 40 and $80 \mathrm{mg}$, and placebo respectively $(p<0.0001$ for both telmisartan doses vs placebo). Furthermore, the rate of transition was significantly reduced in normotensive patients $(p<0.01$ for both doses vs placebo) and after adjustment for changes in SBP, suggesting that telmisartan reduced the transition from incipient to overt nephropathy independently of its blood pressure-lowering effects.

Two further studies - AMADEO and VIVALDI - show that telmisartan slows the progression of nephropathy in diabetic patients with overt proteinuria. ${ }^{45,46}$ In AMADEO ( $\mathrm{n}=860$ ), 1 year's treatment with telmisartan (force titrated to $80 \mathrm{mg} /$ day), was superior to losartan (force titrated to $100 \mathrm{mg} /$ day) in reducing proteinuria (29 vs 20\%, respectively; $p=0.0284]$ ), despite similar blood pressure control in the two treatment groups. ${ }^{45}$ In VIVALDI, both telmisartan (force titrated to $80 \mathrm{mg} /$ day) and valsartan (force titrated to $160 \mathrm{mg} /$ day) reduced 24-hour urinary protein excretion rate by $33 \%$, indicating non-inferiority of telmisartan on this parameter. ${ }^{46}$

\section{Patients with renal impairment}

Telmisartan, 40-80 mg/day, elicited significant blood pressure reductions in patients with mild-tomoderate hypertension $(n=82)$ and with varying severities of chronic kidney disease (ranging from mild/moderate to those requiring maintenance haemodialysis) without deterioration in renal function. ${ }^{47}$

\section{Patients with left ventricular (LV) dysfunction}

In patients with hypertension and mild-tomoderate LV hypertrophy, telmisartan reduces left ventricular mass index (LVMI), posterior and septal wall thickness, and left atrial maximal and minimal volumes. ${ }^{9,48}$ Telmisartan's effects on LVH may occur by mechanisms beyond those involved in blood pressure regulation. ${ }^{49}$

\section{Cardiovascular outcome studies}

Three large cardiovascular outcome studies of telmisartan are currently in progress and are evaluating telmisartan's effects in a highrisk population (ONTARGET), in a highrisk population intolerant of $\mathrm{ACE}$ inhibitors (TRANSCEND) and in combination with usual care in the management of stroke (PRoFESS). ${ }^{50-52}$ 
Figure 3. Incidence of adverse events in patients treated with telmisartan, telmisartan/HCT or placebo. ${ }^{4}$

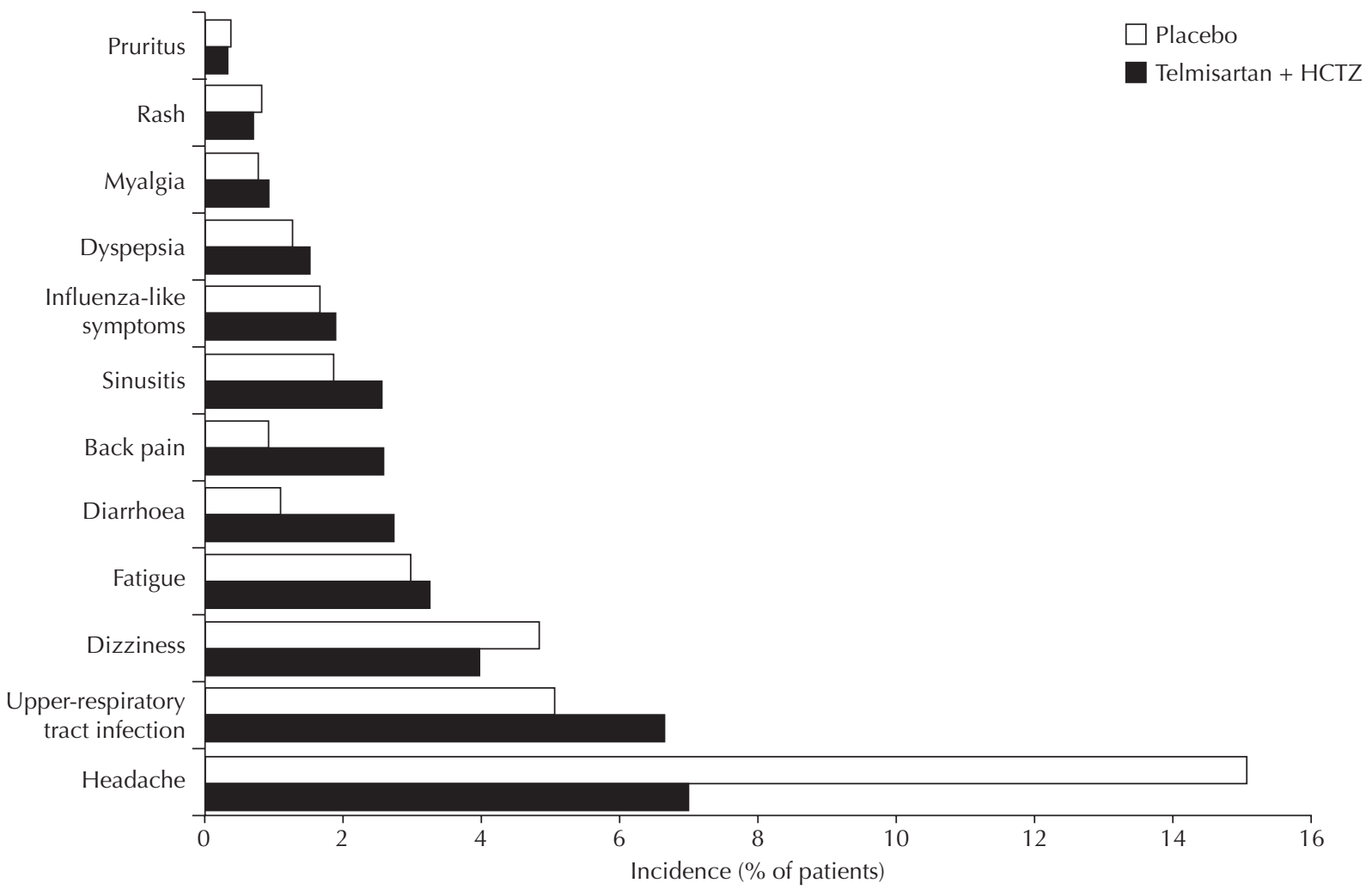

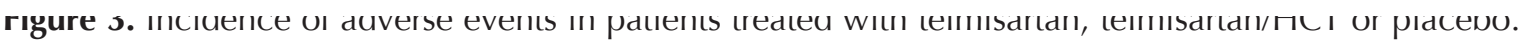

\section{SAFETY AND TOLERABILITY}

Telmisartan is associated with relatively few sideeffects, most of which are mild in intensity and transient in nature. ${ }^{4}$ Fewer discontinuations due to adverse events occurred in patients taking telmisartan compared with placebo-treated patients (2.8 vs 6.1\%). Moreover, patients treated with telmisartan monotherapy and/or telmisartan in combination with HCTZ had a similar incidence of adverse events compared with those receiving placebo. ${ }^{4}$ The most common adverse events in patients receiving telmisartan are shown in Figure 3. A post-marketing surveillance study reported that $1.9 \%$ of patients experienced adverse events over a 6-month treatment period with physicians rating tolerability as very good. 


\section{KEY POINTS}

- Telmisartan is a highly selective 'insurmountable' AT1 receptor antagonist. Its slow dissociation from the $\mathrm{AT}_{1}$ receptor and its long plasma half-life contribute to its extended duration of action.

- Telmisartan provides excellent blood pressure control over 24 hours compared with many other antihypertensives particularly over the last 6 hours of the dosing interval.

- Telmisartan is at least as effective as the ACE inhibitors enalapril, lisinopril, perindopril and ramipril in reducing blood pressure, but is better tolerated.

- Similar or superior reductions in blood pressure are seen with telmisartan compared with atenolol and amlodipine.

- Combinations of telmisartan and HCTZ are well tolerated and provide greater efficacy than telmisartan monotherapy.

- Telmisartan is effective at reducing blood pressure in a broad range of populations including the elderly, patients with type 2 diabetes and the metabolic syndrome, patients with diabetic nephropathy and patients with renal impairment. It also has renoprotective effects.

- Telmisartan, with or without HCTZ, is associated with relatively few side-effects, most of which are mild in intensity and transient in nature.

\section{REFERENCES}

1 Martina B, Dieterle T, Sigle JP et al. Effects of telmisartan and losartan on left ventricular mass in mild-to-moderate hypertension. A randomized, double-blind trial. Cardiology 2003; 99: 169-70.

2 Cupisti A, Rizza GM, D’Alessandro C et al. Effect of telmisartan on the proteinuria and circadian blood pressure profile in chronic renal patients. Biomed Pharmacother 2003; 57 : 169-72.

3 Burnier M, Maillard M. The comparative pharmacology of angiotensin II receptor antagonists. Blood Press Suppl 2001; 1: 6-11.

4 Sharpe M, Jarvis B, Goa KL. Telmisartan: a review of its use in hypertension. Drugs 2001; 61: 1501-29.

5 Israili ZH. Clinical pharmacokinetics of angiotensin II (AT1) receptor blockers in hypertension. 7 Hum Hypertens 2000; 14 Suppl 1: S73-86.

6 Maillard MP, Perregaux C, Centeno C et al. In vitro and in vivo characterization of the activity of telmisartan: an insurmountable angiotensin II receptor antagonist. 7 Pharmacol Exp Ther 2002; 302: 1089-95.

7 Boehringer Ingelheim. Micardis ${ }^{\mathbb{B}}$ (telmisartan). Summary of Product Characteristics.

8 Stangier J, Schmid J, Turck D et al. Absorption, metabolism, and excretion of intravenously and orally administered [14C] telmisartan in healthy volunteers. $\mathcal{F}$ Clin Pharmacol 2000; 40: $1312-22$.

9 Battershall AJ, Scott LJ. Telmisartan. A review of its use in the management of hypertension. Drugs 2006; 66: 51-83.

10 Kurtz TW. Treating the metabolic syndrome: telmisartan as a peroxisome proliferator-activated receptor-gamma activator. Acta Diabetol 2005; 42 Suppl 1: S9-16.
11 Benndorf RA, Rudolph T, Appel D et al. Telmisartan improves insulin sensitivity in nondiabetic patients with essential hypertension. Metabolism 2006; 55: 1159-64.

12 Meredith PA. Optimal dosing characteristics of the angiotensin II receptor antagonist telmisartan. Am f Cardiol 1999; 84: 7K-12K.

13 Kelly-Hayes M, Wolf PA, Kase CS et al. Temporal patterns of stroke onset. The Framingham Study. Stroke 1995; 26: 1343-7.

14 Tofler GH, Muller JE, Stone PH et al. Modifiers of timing and possible triggers of acute myocardial infarction in the Thrombolysis in Myocardial Infarction Phase II (TIMI II) Study Group. 7 Am Coll Cardiol 1992; 20: 1049-55.

15 The sixth report of the Joint National Committee on prevention, detection, evaluation, and treatment of high blood pressure. Arch Intern Med 1997; 157: 2413-46.

16 Neutel J, Smith DH. Evaluation of angiotensin II receptor blockers for 24-hour blood pressure control: meta-analysis of a clinical database. 7 Clin Hypertens (Greenwich) 2003; 5: 58-63.

17 Smith DH, Cramer MJ, Neutel JM et al. Comparison of telmisartan versus losartan: meta-analysis of titration-toresponse studies. Blood Press Monit 2003; 8: 111-7.

18 Mallion J, Siche J, Lacourciere Y. ABPM comparison of the antihypertensive profiles of the selective angiotensin II receptor antagonists telmisartan and losartan in patients with mild-to-moderate hypertension. 7 Hum Hypertens 1999; 13: 657-64.

19 White WB, Lacourciere Y, Davidai G. Effects of the angiotensin II receptor blockers telmisartan versus valsartan on the circadian variation of blood pressure: impact on the early morning period. Am 7 Hypertens 2004; 17: 347-53.

20 Calvo C, Hermida RC, Ayala DE, Ruilope LM. Effects of telmisartan $80 \mathrm{mg}$ and valsartan $160 \mathrm{mg}$ on ambulatory blood pressure in patients with essential hypertension. f Hypertens 2004; 22: 837-46. 
21 Amerena J, Pappas S, Ouellet JP et al. ABPM comparison of the anti-hypertensive profiles of telmisartan and enalapril in patients with mild-to-moderate essential hypertension. 7 Int Med Res 2002; 30: 543-52.

22 Neutel JM, Frishman WH, Oparil S et al. Comparison of telmisartan with lisinopril in patients with mild-to-moderate hypertension. Am F Ther 1999; 6: 161-6.

23 Ragot S, Ezzaher A, Meunier A et al. Comparison of trough effect of telmisartan vs perindopril using self blood pressure measurement: EVERESTE study. F Hum Hypertens 2002; 16: 865-73.

24 Williams B, Gosse P, Lowe L, Harper R. The prospective, randomized investigation of the safety and efficacy of telmisartan versus ramipril using ambulatory blood pressure monitoring (PRISMA I). 7 Hypertens 2006; 24: 193-200.

25 Lacourciere Y, Neutel JM, Davidai G, Koval S. A multicenter, 14-week study of telmisartan and ramipril in patients with mild-to-moderate hypertension using ambulatory blood pressure monitoring. Am $\mathcal{J}$ Hypertens 2006; 19: 104-12.

26 Gosse P, Neutel JM, Schumacher $\mathrm{H}$ et al. The effect of telmisartan and ramipril on early morning blood pressure surge: a pooled analysis of two randomized clinical trials. Blood Press Monit 2007; 12: 141-147.

27 Freytag F, Schelling A, Meinicke T, Deichsel G. Comparison of 26-week efficacy and tolerability of telmisartan and atenolol, in combination with hydrochlorothiazide as required, in the treatment of mild to moderate hypertension: a randomized, multicenter study. Clin Ther 2001; 23: 108-23.

28 Lacourciere Y, Lenis J, Orchard R et al. A comparison of the efficacies and duration of action of the angiotensin II receptor blockers telmisartan and amlodipine. Blood Press Monit 1998; 3: 295-302.

29 Lacourciere Y, Martin K. Comparison of a fixeddose combination of $40 \mathrm{mg}$ telmisartan plus $12.5 \mathrm{mg}$ hydrochlorothiazide with $40 \mathrm{mg}$ telmisartan in the control of mild to moderate hypertension. Am F Ther 2002; 9: 111-7.

30 Freytag F, Holwerda NJ, Karlberg BE et al. Long-term exposure to telmisartan as monotherapy or combination therapy: efficacy and safety. Blood Press 2002; 11: 173-81.

31 Neutel JM, Klein C, Meinicke TW, Schumacher H. Longterm efficacy and tolerability of telmisartan as monotherapy and in combination with other antihypertensive medications. Blood Press 2002; 11: 302-9.

32 Fenton C, Keating GM, Scott LJ. Telmisartan/ hydrochlorothiazide: in the treatment of essential hypertension. Drugs 2003; 63: 2013-26; discussion 2027-8.

33 Lacourciere Y, Gil-Extremera B, Mueller O et al. Efficacy and tolerability of fixed-dose combinations of telmisartan plus HCTZ compared with losartan plus HCTZ in patients with essential hypertension. Int 7 Clin Pract 2003; 57: 273-9.

34 Neutel JM, Littlejohn TW, Chrysant SG, Singh A. Telmisartan/Hydrochlorothiazide in comparison with losartan/hydrochlorothiazide in managing patients with mild-to-moderate hypertension. Hypertens Res 2005; 28 : 555-63.

35 White WB, Giles T, Bakris GL et al. Measuring the efficacy of antihypertensive therapy by ambulatory blood pressure monitoring in the primary care setting. Am Heart $\mathcal{F} 2006$; 151 : 176-84.
36 White WB, Weber MA, Davidai G et al. Ambulatory blood pressure monitoring in the primary care setting: assessment of therapy on the circadian variation of blood pressure from the MICCAT-2 Trial. Blood Press Monit 2005; 10: 157-163.

37 Weber MA, White WB, Giles TD et al. An effectiveness study comparing algorithm-based antihypertensive therapy with previous treatments using conventional and ambulatory blood pressure measurements. $\mathcal{F}$ Clin Hypertens (Greenwich) 2006; 8: 241-50; quiz 251-2.

38 Neldam S, Edwards C. Telmisartan plus HCTZ vs. amlodipine plus HCTZ in older patients with systolic hypertension: results from a large ambulatory blood pressure monitoring study. Am f Geriatr Cardiol 2006; 15: 151-60.

39 Fogari R, Mugellini A, Zoppi A et al. Effect of telmisartan/ hydrochlorothiazide vs lisinopril/hydrochlorothiazide combination on ambulatory blood pressure and cognitive function in elderly hypertensive patients. 7 Hum Hypertens 2006; 20: 177-85.

40 Derosa G, Ragonesi PD, Mugellini A et al. Effects of telmisartan compared with eprosartan on blood pressure control, glucose metabolism and lipid profile in hypertensive, type 2 diabetic patients: a randomized, double-blind, placebocontrolled 12-month study. Hypertens Res 2004; 27: 457-64.

41 Sharma AM, Davidson JA, R. GJ, DeSousa NJ. Comparison of the antihypertensive efficacy of telmisartan/ hydrochlorothiazide vs valsartan/hydrochlorothiazide in high-risk overweight/obese patients with hypertension and type 2 diabetes. Hypertension 2005; 46: 898. Abstract PC.11.

42 Barnett AH, Bain SC, Bouter P et al. Angiotensin-receptor blockade versus converting-enzyme inhibition in type 2 diabetes and nephropathy. N Engl F Med 2004; 351: 1952-61.

43 Barnett A. Preventing renal complications in type 2 diabetes: results of the diabetics exposed to telmisartan and enalapril trial. 7 Am Soc Nephrol 2006; 17: S132-5.

44 Makino H, Haneda M, Babazono T et al. Prevention of transition from incipient to overt nephropathy with telmisartan in patients with type 2 diabetes. Diabetes Care 2007; 30: 1577-8.

45 Bakris G, Burgess E, Weir M, Koval S. Comparative long term effects of two AT1 receptor blockers on proteinuria in patients with type-2 diabetes and overt nephropathy and hypertension: results of the AMADEO trial. Presented at the Annual Meeting of the American Society of Hypertension, Chicago, USA, 19 May 2005.

46 Galle J, Pinnetti S, Wanner C. Antiproteinuric effects of telmisartan versus valsartan in patients with type 2 diabetes and overt nephropathy. Presented at the 21 st meeting of the International Society of Hypertension, Fukuoka, Japan. 15-19 October, 2006.

47 Sharma AM, Hollander A, Koster J. Telmisartan in patients with mild/moderate hypertension and chronic kidney disease. Clin Nephrol 2005; 63: 250-7.

48 Mattioli AV, Bonatti S, Monopoli D et al. Influence of regression of left ventricular hypertrophy on left atrial size and function in patients with moderate hypertension. Blood Press 2005; 14: 273-8.

49 Galzerano D, Tammaro P, del Viscovo L et al. Threedimensional echocardiographic and magnetic resonance assessment of the effect of telmisartan compared with carvedilol on left ventricular mass a multicenter, randomized, longitudinal study. Am 7 Hypertens 2005; 18: 1563-9. 
50 Chrysant SG, Chrysant GS, Desai A. Current status of angiotensin receptor blockers for the treatment of cardiovascular diseases: focus on telmisartan. 7 Hum Hypertens 2005; 19: 173-83.

51 Sleight P. The ONTARGET/TRANSGEND Trial Programme: baseline data. Acta Diabetol 2005; 42 Suppl 1: S50-6.

52 Diener HC, Sacco R, Yusuf S. Rationale, Design and Baseline Data of a Randomized, Double-Blind, Controlled Trial Comparing Two Antithrombotic Regimens (a FixedDose Combination of Extended-Release Dipyridamole plus ASA with Clopidogrel) and Telmisartan versus Placebo in Patients with Strokes: The Prevention Regimen for Effectively Avoiding Second Strokes Trial (PRoFESS). Cerebrovasc Dis 2007; 23: 368-80.
Correspondence:

Stephen I'Anson, Just Medical Media Ltd, 11 Redgrove Park, Cheltenham, Gloucestershire, GL51 6QY, UK.

Email: publisher@justmedicalmedia.com. 